DOI: $10.4274 /$ tpa.46.87

\title{
Osler-Weber-Rendu sendromu ile ilişkili pulmoner arteriyovenöz malformasyon
}

\section{Pulmonary arteriovenous malformation associated with Osler-Weber-Rendu syndrome}

\author{
Yakup Ergül, Kemal Nişli, Aygün Dindar \\ Istanbul Üniversitesi, Istanbul Tıp Fakültesi, Çocuk Sağlı̆̆ı ve Hastaılıları Anabilim Dalı, Çocuk Kardiyolojisi Bilim Dalı, Istanbul, Türkiye
}

Özet

Osler-Weber-Rendu sendromu çocuklarda göreceli sık görülen; cilt, mukoza ve iç organlarda telanjiektazi ve arteriyovenöz malformasyonlarla seyreden vasküler bir displazidir. Bu yazıda akut romatizmal kardit atağı sırasında santral siyanoz, çomak parmak, yüzde, burun mukozasında telanjiektaziler ve sağ akciğerde arteriyovenöz malformasyonu saptanan ve Osler-Weber-Rendu sendromu tanısı alan dokuz yaşında bir erkek olgu sunuldu. Akut romatizmal kardit atağı geçtikten sonra olguya kalp kateterizasyonu yapılarak arteriyovenöz malformasyona "coil" embolizasyonu uygulandı. (Türk Ped Arş 2011; 46: 264-6)

Anahtar sözcükler: Osler-Weber-Rendu sendromu, pulmoner arteriyovenöz malformasyon, romatizmal kalp hastalığı, siyanoz

\section{Summary}

Osler-Weber-Rendu syndrome is a relatively common vascular displasia of children presented with telengiectasias of skin, mucosa, and visceral organs and arteriovenous malformations. We reported a 9-year-old boy diagnosed as having Osler-Weber Rendu syndrome with his central cyanosis, clubbing, facial and nasal mucosal telengiectasias and right pulmonary arteriovenous malformation during an attack of acute rheumatic carditis. After relief of the acute rheumatic carditis attack, his arteriovenous malformation was treated with coil embolisation by cardiac catheterization. (Turk Arch Ped 2011; 46: 264-6)

Key words: Cyanosis, osler-Weber-Rendu syndrome, pulmonary arteriovenous malformation, rheumatic heart disease

\section{Giriş}

Osler-Weber-Rendu sendromu (herediter hemorajik telanjiektazi) tekrarlayan burun kanamaları, mukokutanöz telanjiektaziler ve iç organlarda arteriyovenöz malformasyonlarla (AVM) seyreden otozomal baskın (dominan) kalıtılan bir damar displazisidir (1). Hastalığın görülme sıklı̆ı ilk tanımlandığı yıllarda nadir olarak belirtilse de son zamanlarda 1:5 000-1:10 000 sıklığında olduğu bildirilmektedir (1-3). Hastalığın iç organ tutulumu; akciğer, beyin ve karaciğerde farklı sayılarda AVM'lerden oluşmakta ve çocuklardaki iç organ tutulumu sıklığı tam olarak bilinmemektedir (4). Bu yazıda son iki yıldır burun kanamaları, çabuk yorulma, dudaklarda morluk yakınmaları olan ve akut romatizmal kardit atağı sırasında bu bulgularıyla OslerWeber-Rendu sendromu tanısı alan ve tedavisi düzenlenen dokuz yaşında bir hasta, öykü ve fizik muayenenin önemini vurgulamak amacıyla sunuldu.

\section{Olgu Sunumu}

Dokuz yaşında erkek olgu; ateş, halsizlik ve çabuk yorulma yakınmalarıyla gittiği hastanede yapılan ekokardiyografide (EKO) mitral ve aort kapağında yetersizlik saptanınca, akut romatizmal ateş düşünülerek tarafımıza yönlendirildi. Öyküsünden son iki yıldır çabuk yorulma, öksürük, dudaklarda morluk ve özellikle geceleri tekrarlayan burun kanamalarının oldu-

Yazışma Adresi/Address for Correspondence: Dr. Yakup Ergül, İstanbul Üniversitesi, İstanbul Tıp Fakültesi, Çocuk Sağlığı ve Hastalıkları Anabilim Dalı, Çocuk Kardiyolojisi Bilim Dalı, İstanbul, Türkiye Tel.: +90 2124142000 / 32236 E-posta: yakupergul77@hotmail.com, jacoba_e@yahoo.com Geliş Tarihi/Received: 04-01-2010 Kabul Tarihi/Accepted: 29.03.2010 
ğu öğrenildi. Olgunun daha önce öksürük yakınmasıyla gittiği iki merkezde akciğer grafisi çekilerek pnömoni tedavisi gördüğü ve bir ay önce ateşli bir boğaz enfeksiyonu geçirdiği öğrenildi. Soygeçmişinde babasında tekrarlayan dudak ve burun kanamaları dışında özellik yoktu.

Fizik muayenede; genel durumu düşkün, bilinç açık, vücut ısısı $38,2^{\circ} \mathrm{C}$ (koltuk altı), kapiller dolum zamanı normal, dudaklarda ve dilde belirgin siyanoz ve her iki elinde çomak parmak vardı. Yanaklarda ve burunda telanjiektazileri saptandı. Dolaşım sistemi muayenesinde; kalp tepe atımı 110/dak, kan basıncı 110/40 mmHg ve periferik nabızları doğal olarak ele geliyordu. Dinlemekle S1 ve S2 hafif duyulmakla birlikte S3 yoktu. Mitral odakta 2/6 pansistolik üfürüm ve sol 3-4. interkostal aralıkta erken diyastolik üfürüm duyuldu. Diğer sistem muayenelerinde özellik yoktu.

Laboratuvar bulgularında; hemoglobin $9,5 \mathrm{~g} / \mathrm{dL}$, hematokrit \%31, beyaz küre sayısı $17500 / \mathrm{mm}^{3}$ (\%70 nötrofil \%26 lenfosit, \%4 monosit), trombosit sayısı $513000 / \mathrm{mm}^{3}$, C- reaktif protein (CRP) $146 \mathrm{mg} / \mathrm{L}(\mathrm{N}<5 \mathrm{mg} / \mathrm{L})$, eritrosit çökme hızı 70 $\mathrm{mm} / \mathrm{sa}$, anti streptolizin O (ASO) 800 IU olan olgunun serum biyokimyasında ve boğaz kültüründe patoloji saptanmadı. Santral siyanoza yönelik bakılan hemoglobin elektroforezi normal olan hastanın kapiler oksijen doygunluğu \%88 (oda havasında) olarak ölçüldü ve oksijen solutulması ile artış göstermedi. Elektrokardiyografisi normal olan olgunun göğüs röntgeninde hafif kardiyomegalisi (kardiyotorasik oran \%56) ve akciğer sağ orta bölümünde yuvarlak şekilde $2 \times 3 \mathrm{~cm}$ boyutunda opasitesi vardı. Ekokardiyografide önemli mitral kapak yetersizliği, orta derece aort yetersizliği, sol atriyum ve sol ventrikülde genişleme saptandı. Perikardiyal sıvı görülmedi. Kardit, ateş, CRP, eritrosit çökme hızında yükseklik ve ASO yüksekliği nedeniyle akut romatizmal ateş (ARA) tanısı konulan olguya benzatin penisilin, metil prednizolon, digoksin, furo-

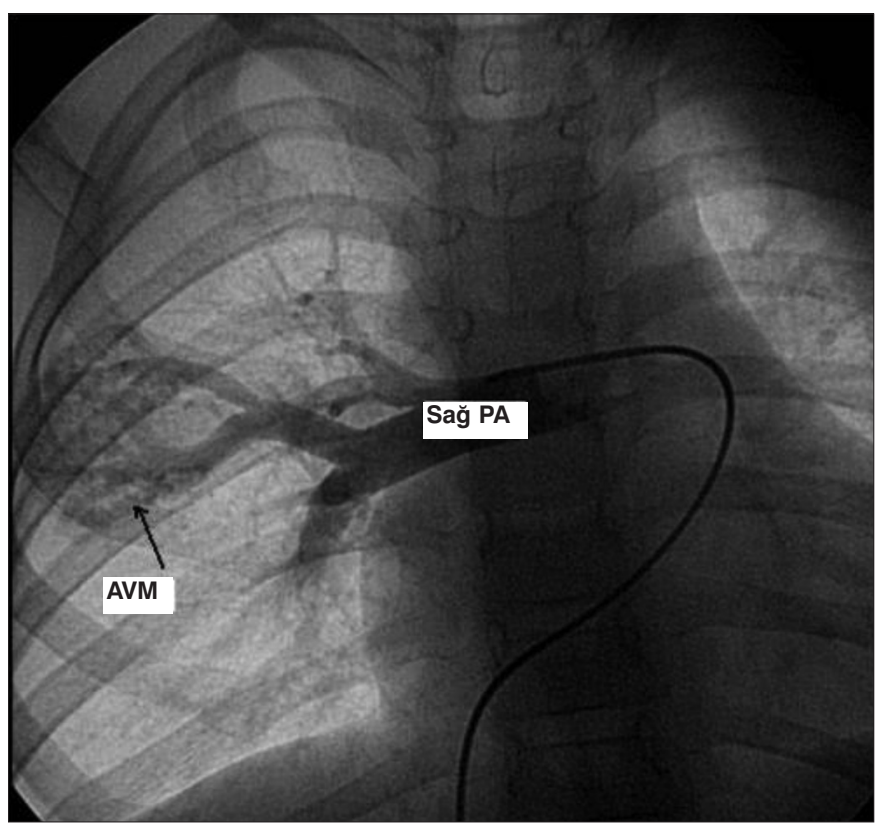

Resim 1. Sağ pulmoner arter (PA) anjiyografisinde akciğer orta zonda, beslenme arterini sağ pulmoner arterden alan arteriyovenöz malformasyon (AVM) semid ve enalapril tedavisi bașlandı. İzlemde kardit bulguları ve akut faz reaktanları azalmakla birlikte siyanozu devam etti. Santral siyanozu, telanjiektazileri ve akciğer grafi bulgularıyla olguda pulmoner AVM veya fistül olabileceği düşünülerek önce kontrastı EKO yapıldı. Sağ önkoldaki venöz yoldan serum fizyolojik verilmesini izleyerek önce sağ atriyum, sağ ventrikül ve ikinci siklusta sol atriyumun kabarcıklarla dolduğu görüldü. Akciğer perfüzyon sintigrafisinde \%23 oranında akciğer içinde şantı düşündüren bulguları olan olguya kontrastlı akciğer tomografisi çekildi. Akciğer parenkim değerlendirmesinde sağ akciğer üst lob posterior pulmoner arter dalından beslenen, üst lob posterior pulmoner ven dalına direne olan $28 \times 24 \mathrm{~mm}$ boyutlarında nidusu, $8 \mathrm{~mm}$ arteri ve $12 \mathrm{~mm}$ veni olan AVM saptandı. Pulmoner AVM, mukokutanöz telanjiektaziler ve tekrarlayan burun kanamaları ile Osler-Weber-Rendu sendromu tanısı konuldu. Diğer iç organlardaki olası tutulumlar açısından yapılan tüm karın kontrastlı tomografisinde ve beyin manyetik rezonans incelemesinde özellik saptanmadı. Olgunun aile öyküsünde babada da tekrarlayan mukokutanöz kanamalar olduğundan tarama amaçlı olarak aile, İç Hastalıkları Anabilim Dalı'na yönlendirildi. Olguda aktif ARA karditi olduğu için kalp kateterizasyonu ertelendi ve olgu poliklinik izlemine alındı. Altı ay sonraki poliklinik kontrolünde ARA kardit bulguları gerileyen ve EKO'sunda hafif aort ve mitral yetersizliği saptanan olguya kalp kateterizasyonu uygulandı. Sağ femoral venden girilerek yapılan selektif pulmoner arter anjiyografisinde sağ pulmoner arterden beslenme arterini alan ve sağ pulmoner vene direne olan AVM görüldü (Resim 1). Olgunun bulguları olup, beslenme arteri büyük olduğundan AVM beslenme arterlerine $8 \times 5 \mathrm{~mm}, 6,5 \times 5 \mathrm{~mm}$ ve $5 \times 4 \mathrm{~mm}$ boyutlarında salınım kontrollü "coil"lerle embolizasyon uygulandı. İşlem sonrası kontrol anjiyografide AVM'nin arteryel beslenmesinin belirgin olarak azaldığı görüldü (Resim 2).

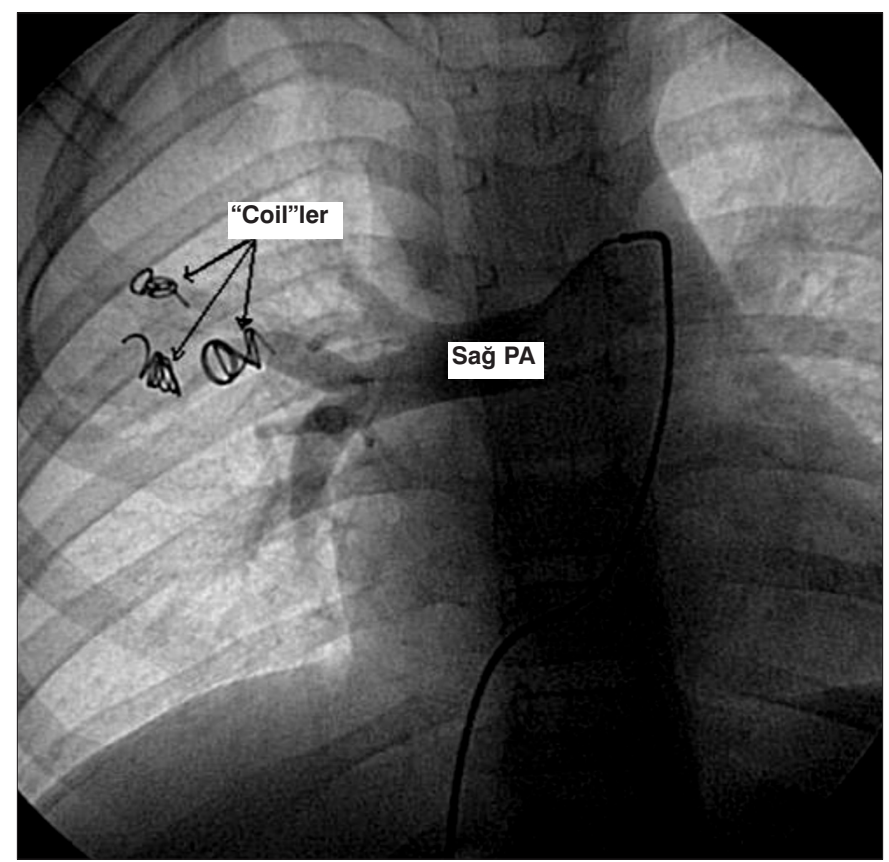

Resim 2. "Coil" embolizasyonu sonrası kontrol sağ pulmoner arter (PA) enjeksiyonu 
Siyanozu da önemli ölçüde azalan olgunun arteryel oksijen doygunluğu \%95'e yükseldi.

\section{Tartışma}

Osler-Weber-Rendu sendromu ilk olarak 1864 yılında tanımlanan, sırasıyla Rendu, Osler ve Weber tarafından ailevi olduğu, telanjiektazilerle seyrettiği ve mukozal kanamalara yol açtığı ortaya konulan otozomal baskın kalııılı bir damar displazisidir (1-3). En sık patolojik bulgu telanjiektaziler olup mukokutanöz kanamalara yol açarken ikinci sık görülen bulgu ise iç organlarda görülen AVM'lerdir. En sık yerleşim yerleri akciğer, beyin ve karaciğer dolaşımıdır (4). Hastalığın tanısı dört ölçütten [kendiliğinden tekrarlayıcı burun kanamaları, mukokutanöz telanjiektaziler, iç organlarda AVM'ler (akciğer, beyin, sindirim sistemi) ve birinci derece akrabalarda Osber-WeberRendu sendromu tanısı] üç veya daha fazlasının gösterilmesiyle konulur (2). Çocukluk çağında bu hastalığın tanısını koymak zor olabilir. Bunun nedeni çoğu olguda ilk 10 yılda mukokütanöz bulguların çok belirgin olmayışı veya gözden kaçışı, en sık bulgu olan tekrarlayıcı burun kanamalarının ise çocuklarda daha çok yerel travma, üst solunum yolu enfeksiyonu ve alerjik hastalıklarla ilişkilendirilmesi olarak sıralanabilir (3-5). Bu tür olgularda ailede genetik tanısı olan hastalar varsa hastalık otozomal baskın kalıtılığı için genetik analiz tanıya yardımcı olabilir (4). Bizim olgumuz da başvuru öncesi iki yıldır burun kanamaları olmasına ve telanjiektazileri olmasına rağmen tanı alamamıştır.

Tüm yaş grupları göz önüne alındığında, hastalığın mukozal tutulumuna bağlı olarak \%90'ında tekrarlayan burun kanamaları ve \%10-33'ünde sindirim sistemi kanamaları görülmektedir $(3,6)$. İç organ tutulumu olarak olguların \%15-33'ünde akciğer, \%5-10'unda beyinde AVM'ler görülebilmekte iken karaciğerde sıklık tam olarak bilinmemektedir $(1,3,4,7)$. Akciğerde AVM, tek bir lezyon şeklinde veya yaygın olabilir. Yașla birlikte özellikle gebelikte büyüyebilir $(3,8)$. Akciğerde AVM'si olan hastalar bazen uzun süre hiçbir bulgu vermeyebilir. Belirti verenlerde solunumsal yakınmalar, egzersiz entoleransı ve siyanoz yaygın bulgulardır $(3,5)$. Ancak bazen ilk bulgu yaşamı tehdit eden akciğer kanaması, sağ-sol şanta bağlı inme veya beyin apsesi olabileceğinden hastalığın erken tanısı ve tedavisi önemlidir $(3,4,8)$. Akciğerde AVM'si olan hastalarda yaşam boyunca inme sıklığı \%30 ve beyin apsesi sıklığı \%5-9 olarak bildirilmekle beraber özellikle beslenme arteri 3 mm'den büyük olanlarda ve çok sayıda olanlarda bu risk artıyor gibi görünmektedir $(8,9)$. Tanı kontrastlı EKO, bilgisayarlı tomografi ve anjiyografi ile konulur. Tedavide AVM'nin transkateter embolizasyonu güvenilir ve etkin bir biçimde kullanılmak- ta olup cerrahiye olan gereksinimi azaltmıştır. Embolizasyon, bulgu versin veya vermesin, beslenme arteri 3 mm'den büyük olan bütün olgularda önerilmektedir. Bu tedaviyle sağ-sol şant ciddi oranda azaltılmakta ve beyin ile ilgili komplikasyon riski de azaltılabilmektedir. Çok yaygın akciğer AVM'si olan hastalarda akciğer nakli düşünülebilir $(8,10)$. Bizim olgumuz yaklaşık iki yıldır mukozal kanamaları, siyanozu, çabuk yorulması ve solunumsal bulguları olmasına rağmen ARA kardit atağı sırasında tanı aldı. Literatürde ARA ile Osler-Weber-Rendu sendromunun beraberliğine rastlamadık. Ancak bunun anlamlı bir birliktelik olmadığını ve sebep-sonuç ilişkisi taşımadığını düşünüyoruz. Olgumuzda sağ akciğerdeki AVM'nin beslenme arteri $8 \mathrm{~mm}$ olduğu için, sağ-sol şanta bağılı komplikasyonları önlemek ve siyanozu azaltmak için transkateter embolizasyon uygulandı.

Sonuç olarak; çocuklarda Osler-Weber-Rendu sendromu tanısı koymak zor olsa da iyi bir öykü ve fizik muayene tanıda çok önemlidir. Santral siyanozla gelen hastada kalp ile ilgili bir neden bulunamıyorsa mutlaka akciğerde AVM araştırması yapılmalıdır. Akciğerde AVM saptanan olgulara; yakınmasız bile olsa olası beyin komplikasyonlarından dolayı, beslenme arteri $3 \mathrm{~mm}$ 'den fazlaysa, transkateter embolizasyon işlemi uygulanmalıdır.

\section{Kaynaklar}

1. Plauchu H, de Chadarevian JP, Bideau A, et al. Age-related clinical profile of hereditary hemorrhagic telangiectasia in an epidemiologically recruited population. Am J Med Genet 1989; 32: 291-7.

2. Shovlin CL, Guttmacher AE, Buscarini E, et al. Diagnostic criteria for hereditary hemorrhagic telangiectasia (Rendu-Osler-Weber syndrome). Am J Med Genet 2000; 91: 66-7.

3. Sharathkumar AA, Shapiro A. Hereditary haemorrhagic telangiectasia. Haemophilia 2008; 14: 1269-80.

4. Mei-Zahav M, Letarte M, Faughnan ME, et al. Symptomatic children with hereditary hemorrhagic telangiectasia: a pediatric center experience. Arch Pediatr Adolesc Med 2006; 160: 596-601.

5. Guttmacher AE, Marchuk DA, White RI Jr. Hereditary hemorrhagic telangiectasia. N Engl J Med 1995; 333: 918-24.

6. Ingrosso M, Sabba C, Pisani A, et al. Evidence of small-bowel involvement in hereditary hemorrhagic telangiectasia: a capsule-endoscopic study. Endoscopy 2004; 36: 1074-9.

7. Vase P, Holm M, Arendrup H. Pulmonary arteriovenous fistulas in hereditary hemorrhagic telangiectasia. Acta Med Scand 1985; 218: 105-9.

8. Cottin V, Plauchu H, Bayle JY, et al. Pulmonary arteriovenous malformations in patients with hereditary hemorrhagic telangiectasia. Am J Respir Crit Care Med 2004; 169: 994-1000.

9. Maher CO, Piepgras DG, Brown RD Jr, et al. Cerebrovascular manifestations in 321 cases of hereditary hemorrhagic telangiectasia. Stroke 2001; 32: 877-82.

10. Faughnan ME, Palda VA, Garcia-Tsao G, et al. International guidelines for the diagnosis and management of hereditary hemorrhagic telangiectasia. J Med Genet 2011; 48: 73-87. 